\title{
Contraconocimiento y pandemias de credulidad en la Sociedad Red: el papel del periodismo en la búsqueda de la verdad en los entornos digitales
}

\author{
Carlos ElíAs PÉREZ \\ Universidad Carlos III de Madrid \\ celias@hum.uc3m.es
}

Recibido: $16 / 11 / 2012$

Aceptado: 05/03/2013

\begin{abstract}
Resumen
Internet ha modificado profundamente la relación que siempre ha existido entre el conocimiento establecido y la opinión pública. Ha propiciado la aparición del ciber-rumor: cualquiera puede subir su opinión respecto a cualquier asunto a la web. Estos rumores infundados pueden ser más efectivos que los mensajes de los verdaderos expertos. Se crea lo que se denomina contraconocimiento, un fenómeno emergente en la sociedad red. Mucho contraconocimiento es inofensivo: que la reina de Inglaterra es extraterrestre o que Elvis Presley está vivo. Pero otro es muy dañino. Este artículo estudia cómo el contraconocimiento usa una base científica para conseguir credibilidad. Analiza varios casos controvertidos, como vacunas y gripe $\mathrm{A}$, cáncer y teléfonos móviles, etc. Y cuantifica qué información puede obtenerse si usamos para informarnos Google-web, Google-blog o Youtube. Se observan diferencias sustanciales entre los distintos canales, aunque puede generalizarse que la información procedente de la pseudociencia es más abundante de lo que podría pensarse. Se analizan cuáles son los parámetros para que una historia triunfe en la red -independientemente de su verosimilitud- y se recomienda que las universidades sean más activas en contrarrestar el mensaje pseudocientífico.
\end{abstract}

Palabras clave: contraconocimiento, sociedad red, periodismo científico, Google

\section{Counterknowledge and Credulity Pandemics in Network Society: the Role of Journalism in Search of Truth in Digital Environment}

\begin{abstract}
Internet has modified in deep the traditional relationship between academic knowledge and public opinion. It has developed the cyber-gossip: a word which means everybody can write what ever they want in the web even without an academic approach. Many of the gossips that go round the web are harmless, such as Elizabeth the Queen is an alien or Elvis Presley is still alive. However, the gossips with a scientific background are harmful because the scientific credibility acts as guarantor of the gossip. This is defined as counterknowledge, an emerging trend in network society. The online public opinion believes in them. This article analyzes some "case study" of this type of gossip. Sometimes theses cyber-gossips could be more valuable -in terms of effectiveness to persuade population- than the real expertise messages spread out by university professors and their webs. This article analyzes some controversial case studies, such as vaccine and A Flu or the relationships between cancer and mobiles, among others. We study which information we can obtain if use different paths for finding it such as Goolge-web, Goolge-blog and Youtube. We can detect some differences among them. Nevertheless we can generalize that there is much more information about pseudoscience than proper science itself. We point out which parameters are interesting for getting a good position in the web. We recommend that universities should use web techniques as videos in Youtube or lecture's blogs for disseminate the scientific thoughts and the academic approach among the online public opinion. Academician should counteract the pseudoscientific approach which is dominant in the web.
\end{abstract}

Keywords: counterknowledge, network society, scientific journalism, Google

\section{Referencia normalizada}

ELÍAS PÉREZ, Carlos (2013): “Contraconocimiento y pandemias de credulidad en la Sociedad Red: el papel del periodismo en la búsqueda de la verdad en los entornos digitales". Estudios sobre el Mensaje 
Periodístico. Vol. 19, Núm. 2 (julio-diciembre), págs.: 667-681. Madrid, Servicio de Publicaciones de la Universidad Complutense.

Sumario: 1. Introducción. 2. Materiales y Metodología. 3. Resultados: análisis de casos-estudio; 3.1. La aparición del ciberrumor: el caso de la monja-bulo; 3.2. Periodismo, ciencia y contraconocimiento: el caso de Andrew Wakefield; 3.3. Diferencias entre Google-web y Google-blog. 4. Discusión. Ciencia para avalar el contraconocimiento. 5. Conclusión. ¿Quién jerarquiza a Google? Conocimiento vs. contraconocimiento. 6. Referencias

\section{Introducción}

En 2012 se produjo un fenómeno que, aunque inadvertido, tendrá consecuencias: la Enciclopedia Británica dejó de editarse en papel. Sólo se podrá acceder mediante suscripción. Antes de la aparición de Internet, para saber quién era Carlo Magno que para qué sirven las vacunas, sólo había que conocer el orden alfabético. Bastaba buscar el término en la Enciclopedia Británica (o la Espasa española) para conocer la verdad. Ambas siempre fueron fuentes de total solvencia y autoridad para los periodistas que queríamos contextualizar un dato o un hecho.

Pero si buscamos "vacuna" en Google cómo saber cuál es la entrada donde ofrece la información avalada por la ciencia. Los motores de búsqueda digital son algoritmos matemáticos que se basan en elementos como blogs enlazados a esa dirección web, número de palabran con hipertexto que contiene, la dirección geográfica desde donde se realiza la búsqueda o, simplemente, los términos más buscados desde ese ordenador. Ello propicia un avance sin precedentes de que lo muchos denominamos contraconocimiento y definido por el profesor de la London School of Economics Damian Thompson como "información errónea, presentada de modo que parezca basada en hechos; presentada con tal eficacia que el siglo XXI se enfrente a una pandemia de credulidad. Ideas que en su forma original y bruta florecieron únicamente en los arrabales de la sociedad hoy las consideran en serio incluso personal cultas del mundo occidental", (Thomson, 2009: 9-10).

Esto no es nuevo. En la Inglaterra georgiana un médico de Londres vendía una medicina que no sólo curaba "el dolor de cabeza y de estómago", sino también el pelo rojo y las pecas (Porter, 2000: 95). Aquellos medicastros usaban la ciencia para avalar su estafa. Curiosamente no usaban el curanderismo, la fe o la magia, sino el aval científico. Lo mismo sucede hoy con la homeopatía o las pulseras magnéticas. Aquellos "pseudomédicos" se graduaban con títulos falsificados y cualificaciones profesionales inventadas. Lo mismo sucede ahora con los expertos en magnetoterapias u homeopatía o Feng Sui. Roy Porter en su libro sobre la historia de la charlatanería en la medicina británica señala que a principios del XIX la profesión médica se sintió atacada "por enjambres de emprendedores astutos, farmacéuticos sin formación, irregulares e itinerantes que hacen fortuna (Porter, 2000: 193)". Sólo se logró expulsarlos de la medicina tradicional gracias a la campaña de un cirujano, Thomas Wakley, que utilizó su revista, The Lancet -hoy en día una de las más prestigiosas del mundo- para atacar "el satánico sistema de curandería". Criticó al Colegio de Médicos, calificándolo de "vil", al de cirujanos de "vampiros" y al de farmacéuticos de "arpías" por no refutar a los charlatanes. Curiosamente, en estos momentos muchas farmacias con licencia en las 
que, supuestamente, debe existir un titulado oficial con aval científico, también venden productos homeopáticos. Incluso, algunas universidades españolas han intentado y, en algún caso, conseguido- introducir estudios de homeopatía. Cualquier químico de primero de carrera sabe que la homeopatía no tiene sustento científico alguno. Las redes sociales han conseguido parar iniciativas de contraconocimiento en universidades oficiales españolas. La web y el blog del círculo escéptico tienen la llamada lista de la vergüenza ${ }^{1}$, en la que aparecen las iniciativas de conrtaconocimiento más disparatadas avaladas por la "ciencia oficial": desde la cátedra de homeopatía y laboratorios Bairon en la Universidad de Zaragoza hasta el curso de auriculoterapia en la Universidad de Santiago o kinesiología holística del colegio de fisioterapeutas de Castilla y León. La cátedra de homeopatía en la Universidad de Zaragoza suscitó un fuerte rechazo, pero no, como cabría esperar de la comunidad científica o académica, sino de los medios de comunicación tradicionales. El diario Público (28-10-2010) titulaba: "La homeopatía se paga una cátedra en la universidad". Y, como subtítulo: "Un potente laboratorio financiará la enseñanza de esta pseudociencia en las aulas públicas".

Algo similar ocurrió en el diario El País donde el escándalo de sus lectores (más de 600 comentarios críticos en la web en unas pocas horas) ante un artículo neutral sobre la homeopatía titulado: "La homeopatía ¿Quimera o ciencia?" (El País 06-03-2010) desencadenó las excusas de su defensora del lector en aquel momento, Milagros Pérez Oliva. La defensora tituló su artículo "Homeopatía de la creencia a la evidencia" ( $E l$ País, 14-03-2010). El subtítulo dejaba claro el sentido: "En periodismo médico no cabe equidistancia entre la evidencia científica y las teorías no demostradas. Los productos homeopáticos se aprueban sin estudios de eficacia" El artículo criticaba, con razón, las formas de proceder del periodista que firmó el reportaje, Josep Garriga, por aplicar algo que se enseña mal en las facultades de periodismo pues favorece el contraconocimiento, la neutralidad. Garriga se defendió así de su reportaje a favor del contraconocimiento: "Preparé el reportaje durante casi un mes y admito que no conocía nada sobre este tema, pero tenía varias cosas claras. Primera, debía hablar con ambas partes, partidarios y detractores. Segunda, no adoptaría ninguna conclusión, sino que debería ser el lector quien llegara a ella. Y tercera, sólo hablaría con licenciados en medicina especializados en homeopatía" (El País, 14-03-2010). ¿Un periodista debe hablar con partidarios y detractores de la teoría del flogisto o la teoría heliocéntrica?

El periodista Josep Garriga, según aparece en el artículo citado de la defensora del lector, no está de acuerdo con algunos lectores muy incisivos, "que comparan la homeopatía con la brujería, la quiromancia o la imposición de manos". Y lo argumenta así: "Nada menos que seis universidades españolas de indudable prestigio realizan o han realizado másteres en homeopatía; el Colegio de Médicos de Cataluña tiene una sección sobre homeopatía y la Organización Médico-Colegial (OMC) considera su práctica un acto médico. Y aunque la homeopatía carezca de evidencia científica, la propia Sociedad Catalana de Medicina Familiar y Comunitaria la recomienda para nada menos que 30 patologías" (El País, 14-03-2010).

${ }^{1}$ http://www.listadelaverguenza.es/ (consultado última vez 15/05/2012) 
Obviamente en este caso tiene razón el periodista. Parece que siguen siendo válidas las críticas de Thomas Wakley, fundador de The Lancet, cuando, recuerdo, en el siglo XIX calificó al colegio de médicos inglés de "vil", al de cirujanos de "vampiros" y al de farmacéuticos de "arpías" por no refutar a los charlatanes. The Lancet se especializó en revelar ingredientes secretos de las patentes de las medicinas y en invitar a los lectores a poner en evidencia a los curanderos de su barrio. Así influyó en la Ley de Farmacia de 1868 que prohibió legalmente a los curanderos vender venenos y drogas adictivas al público (Porter, 2000: 206). El diario El País también zanjó la polémica, en el periodismo tradicional de calidad, cuando publicó el reportaje "Sanidad concluye que el principal efecto de la homeopatía es placebo" (El Pais, 19-122011). Unos meses antes el diario Público se hizo eco del "suicidio homeopático" en el que un grupo de activistas a favor del conocimiento que sigue el método científico, tomó grandes sobredosis de pastillas homeopáticas para demostrar que no tienen ningún efecto: "El suicidio homeopático no mata" (Público 06/02/2011).

La prevalencia de la explicación científica parecía un tema superado en el siglo $\mathrm{XX}$, no solo en las universidades de calidad sino, incluso, en los medios de comunicación, hasta que Internet ha vuelto a poner en la palestra a los charlatanes y el contraconocimiento en este siglo XXI. De ahí las iniciativas como el suicidio homeopático o de "escépticos en el pub" en la que los científicos intentan proteger a la población (como en el XVIII) de la magia y la irracionalidad. La web no diferencia el conocimiento bien asentado del alternativo, en el sentido de marginal y sin fundamento. En la web gana aquello que Google pone en primer lugar y, normalmente, es lo más enlazado y con más visitas. En un momento en el que La información 2.0 puede ser elaborada directamente por el ciudadano al margen de los medios de comunicación tradicionales, las universidades o los centros de investigación. El concepto de opinión pública se modifica en Web 2.0 con el de "inteligencia colectiva" (Pierre Lévy, 1997) o "multitudes inteligentes" (Howard Rheingold, 2003). Ya no hablamos de responsables activos de los contenidos para lectores pasivos; sino de "lectura beta", un concepto en el que el propio lector puede reelaborar (editar) en la red el texto escrito por el experto y volcarlo editado por él. Aquí el charlatán que dice.

¿Qué posibilita este cambio de paradigma? En primer lugar, uno de los integrantes de la cultura convergente, la convergencia mediática (Jenkins, 2008: 14). En la Red se da una globalización de los contenidos pero también una convergencia y sinergias de los medios de comunicación: blogs de anónimos ciudadanos se enlazan con las webs de la NASA o de las universidades, creando nuevos contenidos. El nuevo significado de convergencia, no se refiere tanto a convergencia de soportes mediáticos - tal y como era definido a principios de este siglo XXI- como, sobre todo, a un cambio cultural, liderado por la Red, en el que los consumidores mediáticos buscan otras informaciones, establecen nuevas conexiones entre contenidos mediáticos dispersos y los propios espectadores-usuarios-receptores-finales se convierten en emisores. Es decir, la convergencia no se produce en aparatos mediáticos, por muy sofisticada que sea su tecnología, sino en el cerebro de los emisores y receptores.

El otro nuevo concepto que aparece en la nueva Sociedad Red es el de "cultura participativa": opuesta al antiguo esquema de "espectador mediático pasivo". Ahora ya no 
puede hablarse de productores y consumidores mediáticos, como entes separados, que desempeñan funciones distintas. Todos somos ahora potenciales participantes activos.

El último término que me interesa exponer es el de "inteligencia colectiva (Lévi, 1997)". Este concepto parte de la premisa de que ninguno de nosotros puede saberlo todo. Especialmente en un mundo interconectado en el que existe más información de la que el cerebro humano puede abarcar. Sin embargo, cada uno de nosotros sabe algo y de algo, de forma que lo mejor es aprovechar las redes sociales cibernéticas (ahora más avanzadas con la Web 2.0) para construir un conocimiento en el que todos compartamos nuestras experiencias, juntemos las piezas y demos luz a una información nueva más exacta. Estas conversaciones en la red crean un "murmullo" cada vez más valorado en la industria mediática y que definirá su futuro en los próximos años. Sin embargo, no existe fuente de autoridad. Si el conocimiento provenía de la enciclopedia británica o de Espasa Calpe española lo podíamos dar por seguro -y, por ejemplo, incluir la cita sin problema en una noticia periodística-. Pero Wikipedia no nos merece la misma confianza y sería desafortunado usarlo como fuente en un periódico de calidad.

Una de las mayores falacias de la sociedad red es que en su entorno podemos informarnos sobre cualquier asunto. Accedemos a muchas páginas -es cierto-, pero no queda tan claro que podamos informarnos. La inteligencia colectiva y la audiencia activa/participativa propician un interesante fenómeno: las reglas para que una historia tenga éxito en la red no siguen los parámetros de verosimilitud o el contraste de fuentes, sino el de la espectacularidad. Cualquiera puede convertirse en protagonista colgando un video en Youtube. Ese fenómeno lo observamos en el caso del anónimo pastor Terry Jones, que en 2010 casi propicia una guerra mundial por querer quemar un Corán en su casa y difundirlo en la web. Pero, en general, aunque pudo provocar un desastre mundial real, no transformó la visión o las creencias de la opinión pública virtual.

Sin embargo, la Red puede propiciar en la opinión pública virtual una metamorfosis que le haga modificar sus comportamientos sociales. Básicamente, porque no tiene los elementos de juicio para discernir entre lo cierto y lo falso. Aquí las universidades deberían jugar un papel fundamental difundiendo sus resultados científicos en la web, como ya lo hacen las distintas unidades de cultura científicas a través de los sitios webs de las universidades. Es cierto que las universidades se están uniendo para divulgar mejor sus resultados: en España tenemos la plataforma SINC (Servicio de Información y Noticias Científicas), en Europa disponemos de AlphaGalileo (noticias de investigación de las universidades y centros de la UE); y de Eurekalert, perteneciente a la Academia Americana para el Avance de la Ciencia, que difunde noticias procedentes de universidades y centros de investigación de todo el mundo. Sin embargo, la posición de estas webs y de estas noticias no es suficientemente dominante cuando tratamos de buscar en Google un asunto científico controvertido.

\section{Materiales y Metodología}

En esta investigación se pretende analizar cómo se adapta la comunicación de la ciencia y, sobre todo, las fuentes científicas, al cambio radical que en la cultura mediática está suponiendo el nuevo entorno de la sociedad red (Castells, 1996). Emergen para- 
digmas como el de la cultura convergente, el murmullo mediático, la cultura participativa o la inteligencia colectiva y donde buscadores como Google o Youtube se convierten en medios de comunicación por sí mismos. Se ha elegido una metodología de "estudio de caso -fuentes y noticias concretas-" y se ha analizado cómo se comportan esos casos seleccionados a la luz de los nuevos paradigmas.

Se ha sondeado cómo se comporta Google como fuente para buscar información científica, teniendo en cuenta que cada día aumenta la cantidad de periodistas -y de personas que conforman la opinión pública- que usan los buscadores para informarse. Se ha diferenciado entre la web y la blogosfera, ya que se ha considerado que la web es más oficial e institucional, mientras que la blogosfera se relaciona más con la opinión. También se ha analizado el impacto de Youtube. Se han seleccionado científicos polémicos y términos científicamente controvertidos como "vacunas" y "gripe A", "transgénico" o "móviles y cáncer". Se han introducido los términos en Google-web y en Google-blog analizando si existen divergencias entre los enfoques y perfiles encontrados en ambas herramientas.

\section{Resultados: análisis de casos-estudio}

\subsection{La aparición del ciberrumor: el caso de la monja-bulo}

La inteligencia colectiva es un concepto interesante desde la teoría, pero en la práctica deja a la opinión pública sin una tutela efectiva desde los expertos acreditados en el conocimiento, que durante siglos han sido las universidades. Y, en ese contexto, aparece con la mayor naturalidad el ciberrumor. De entre todos los ciberrumores que pueden aparecer, me interesa aquel que aparece en la esfera pública virtual pero que tiene consecuencia en la realidad real. Sobre todo si es de carácter científico, puesto que la población, ni muchas veces los periodistas, están en condiciones de rebatirlo.

En Internet podemos encontrar páginas que afirman que Elvis Presley está vivo o que la Reina de Inglaterra tiene un linaje extraterrestre. Teorías conspirativas sobre la muerte de Marilyn Monroe o sobre el inminente fin del mundo. El asunto cambia cuando hablamos de conocimiento científico. Aquí encontramos desde los excelentes blogs de los científicos de la NASA hasta las web de las universidades. Normalmente en la Red tiene éxito quien personaliza el mensaje. Si el personaje puede presumir de cierta solvencia, ya es un gran promotor de ciberrumores. Uno de estos personajes puede ser Rauni Kilde, ex ministra de Sanidad finlandesa quien no duda en subir vídeos y blogs en los que nos alerta del desastre apocalíptico que amenaza a la Tierra. Kilde, licenciada en Medicina en 1967, ha escrito varios libros sobre ovnis, y cuenta en Internet, sin el menor rubor, cómo ha tenido 140 encuentros con los extraterrestres y cómo le han salvado la vida en tres ocasiones. Obviamente, Kilde no aparecerá en la Enciclopedia Británica (Web 1.0), pero sí tiene una entrada bastante completa en Wikipedia (Web 2.0) con enlaces a sus videos y entrevistas ${ }^{2}$. Aparecer en Wikipedia le da, para la opinión pública menos formada, pero que constantemente navega por el ciberespacio, el halo de credibilidad que antes otorgaba aparecer en la Enciclopedia

${ }^{2}$ Consultada por última vez en noviembre de 2011. 
Británica o en nuestra española Enciclopedia Espasa. La mayoría de los profesores universitarios (al menos los españoles) ni siquiera aparecemos en Wikipedia. Por tanto, desde el punto de vista del posicionamiento de nuestro mensaje ante la opinión pública virtual partimos en desventaja.

Kilde habla en sus videos, muy seguidos en la web, sobre la conspiración que generó el atentado del 11S, la erupción del volcán de Islandia y sus extrañas conexiones o por qué no hay que vacunarse contra la gripe A, porque, según su versión, la vacuna pretende matar a millones de personas. Cuando alguien lee en Wikipedia que un personaje de la exitosa serie de televisión Expediente $X$ está inspirado en Kilde, puede que deje de hacerle caso. Sería otra friki más de los que pueblan el universo del ciberespacio. Esa información se queda ahí y, en el mejor de los casos puede que no tenga más consecuencias. Sin embargo, otros aparecen con igual naturalidad en la esfera virtual pero sus bulos no son tan fáciles de desenmascarar.

Uno de los factores que más merecen ser investigados es la percepción de riesgo para la salud que la opinión pública obtiene a partir de la representación mediática de es enfermedad o de los riesgos de contraerla (Aguilera y Pindado, 2006).

En el otoño de 2009 la población del hemisferio norte respiraba inquieta por la posible repercusión que la aparición de la gripe A podría tener en la salud. La situación sanitaria era grave y fue calificada de pandemia por la Organización Mundial de la Salud (OMS). En el momento en el que la OMS, el ministerio español de Sanidad o los distintos científicos expertos en virología intentaban concienciar a la población de la importancia de la vacunación, una anónima monja colgó un vídeo casero en Youtube instando a no vacunarse. El video, titulado Campanas por la gripe A, estaba protagonizado por una benedictina, Teresa Forcades, licenciada en Medicina pero interesada en terapias alternativas. Obtuvo cientos de miles de visitas, fue enlazado a cientos de webs y difundió la delirante hipótesis de que la vacuna era peligrosa y que las farmacéuticas "y grupos que quieren dominar el mundo" pretendían aniquilar a través de ellas a una parte de la población. Forcades no parecía una loca iluminada como Kilde, sino que vestía de monja y, que se sepa, nadie de la jerarquía católica la ha desautorizado. Por lo tanto, tiene una credibilidad añadida.

Tras el éxito del video de Youtube, los medios de comunicación tradicionales, entre ellos, radio y televisión, entrevistaron a la monja, de modo que su mensaje llegó a millones de personas. Los cortes de las entrevistas en televisión también se subieron a Youtube, extendiendo aún más la idea del peligro de la vacuna en la red. Cientos de blogs y miles de comentarios en la web dieron la razón virtual a la monja calificada entre la opinión pública virtual como "una gran heroína de nuestro tiempo" como, por cierto, también definen a Kilde muchos internautas: "una valiente científica". Las redes sociales actuaron como amplificadores de lo que aparecía en Google-web, Google-blog y Youtube, demostrando que son los emergentes medios de comunicación de masas (Flores Vivar, 2009).

Algunos expertos en enfermedades infecciosas, como el catedrático de la Universidad Complutense José Manuel Sánchez Vizcaíno, consideró que ese video de la monja fue una de las causas por las que un porcentaje tan bajo de la población española se vacunó contra la gripe A y por el que sobraron -y se tuvieron que tirar- tantas 
vacunas $^{3}$. En el caso de que el virus mute a uno más dañino, el mensaje virtual habrá tenido funestas consecuencias reales: la tasa de españoles vacunados es más baja que en otros países. El dinero gastado por el Gobierno en comprar vacunas que no se utilizaron por culpa del pánico desatado por la monja en Youtube ascendió a varios millones de euros.

Es cierto que la prensa de calidad (en papel) arremetió contra el vídeo. En un reportaje de El País (01/11/2009) titulado "Desmontando a la monja-bulo", se explicaba que la historia tuvo éxito porque reúne los elementos de una buena trama conspiratoria que tanto gustan a la audiencia virtual: una víctima, que en este caso era la humanidad, la verdad científica, los pobres del mundo; los villanos, la industria farmacéutica y la OMS; y el héroe, en este caso la monja.

José María Martín Moreno, catedrático de Medicina Preventiva y Salud Pública de la Universidad de Valencia, afirmaba en el citado reportaje: "Creo en la libertad de expresión y no dudo de la buena voluntad de esta persona. Hace algunas afirmaciones que pueden tener verosimilitud, pero a su vez comete multitud de inexactitudes. Habla del riesgo de meter a la población virus vivos insinuando intenciones devastadoras (parece desconocer que en nuestro medio las vacunas no contienen virus vivos, sino que son inactivadas), sugiere terribles riesgos de los adyuvantes y otros extremos que, sin hacer juicio de intenciones, al menos muestran serio desconocimiento de la materia".

Otro de los entrevistados fue Juan Martínez Hernández, experto en Medicina Preventiva y asesor científico de la Organización Médica Colegial. En su opinión, la monja Forcades mezcla las cosas "con un evidente propósito de desprestigiar la vacunación". Sin embargo, desde el punto de vista del éxito del video en la web, la opinión más certera la ofrece Pilar Pérez Breña, jefa de Virología del Centro Nacional de Epidemiología: "Uno supone que por ser monja y por estar en un convento no puede mentir o no tener razón. Pero no tiene sentido que la industria farmacéutica quiera matar a sus propios clientes".

Todos los expertos consultados por El País para el reportaje refutaban las ideas de la monja, pero había que tener mucha formación para rebatir los argumentos de una benedictina vestida como tal, que hablaba desde un convento, que elige como fondo para ser filmada una pared con la pintura de un santo y que, además, usa terminología científica y se presenta a sí misma como médica. El nuevo entorno virtual no está diseñado para seleccionar la información verdadera y un video como éste tiene todas las posibilidades de triunfar entre la opinión pública virtual que, después, actuará en la vida real, según ha sido instruida en el ciberespacio.

\subsection{Periodismo, ciencia y contraconocimiento: el caso de Andrew Wakefield}

Cuando El País colgó su artículo del diario de papel en su web, muchos comentarios fueron, curiosamente, para defender a la monja. Su retórica había superado a la de los verdaderos expertos. Un video casero que prácticamente no había costado dinero, des-

3 Conferencia en el curso de Periodismo Científico organizado por la Universidad de Murcia y el periódico La Verdad en octubre de 2010. 
trozó las millonarias campañas publicitarias de los gobiernos. Esto sería positivo si la información fuera cierta, pero en este caso no fue así. Internet nos confunde, no nos informa.

Una de las lecciones más interesantes que podemos extraer de este caso es que fue un periódico de papel, con un periodista -químico de formación y especializado en salud-, quien fue capaz de desentrañar la historia del fraude de la monja-bulo. Quien no hubiera leído ese reportaje, o carezca de suficientes conocimientos científicos, creerá a la monja ¿Qué nos quedará cuando toda la información sólo pueda encontrarse en la web y la información de calidad sea de pago? ¿Qué video puede competir en Youtube con éste? ¿El de un catedrático de universidad que grabe otro desde su despacho?

Este es un asunto muy interesante. Los catedráticos de universidad no tuvieron problemas para hablar con El País, pero ninguno llamó al gabinete de prensa de su universidad para grabar un video rebatiendo a la monja y colgarlo en Youtube. No se quiso participar de esas nuevas herramientas, pero una cada vez mayor parte de la opinión pública sólo consume Internet. Los académicos tendrían que rebatir ese tipo de mensajes desde sus universidades.

Uno de los aspectos más preocupantes de la nueva opinión pública mundial es que cada vez es más virtual; es decir, se informa casi exclusivamente en el ciberespacio. Google como medio de información -no como medio informativo- en sí mismo es un enfoque que, hasta ahora, no habíamos contemplado desde las facultades de periodismo.

Si se busca en Google "vacuna" y "gripe A", el término que te recomienda el buscador en primer lugar es "efectos secundarios"." En ese entorno, el video descrito de la monja aparece destacado. Las primeras posiciones (tanto en relevancia como en reproducción) son de charlatanes similares a la monja mencionada que nos previenen sobre los peligros de la vacunación. En la web (no en la blogosfera ni en Youtube) aparecen también páginas web oficiales, pero compiten en jerarquía con blogs claramente anticientíficos.

Si buscamos información sobre ideas científicas controvertidas -cáncer de próstata y masturbación- existe un dominio claro de webs que señalan que la masturbación frecuente previene el cáncer de próstata, pero también se cuela noticias científicas calificadas como ciencia amarilla (Elías, 2009), y que concluyen lo contrario (Dimitropoulou et al, 2009). ¿A qué atenerse? ¿A lo que aparece en primera posición? ¿A lo más enlazado? La estrategia de Google para jerarquizar la información no se basa en la veracidad, sino en lo que pagan por posicionarse determinados clientes dueños de las web y, sobre todo, en lo enlazada que esté una página o un blog a otras páginas. Vuelve a repetirse el mito de que la cita implica mayor veracidad. Una anécdota importante en este sentido (de cómo se puede pervertir el sistema, aunque en este caso a favor de la ciencia) se dio en 2010 cuando todos los blogueros del círculo escéptico se unieron para crear una web donde dijera claramente que la homeopatía es una pseudociencia, la enlazaron a sus blogs y agregadores, consiguiendo que se situara en ter-

${ }^{4}$ Consultado periódicamente desde diciembre de 2009 hasta noviembre de 2011 
cer lugar en las búsquedas de Google sobre homeopatía, la inmensa mayoría de las cuales son favorables a este timo con presunto aval científico. Para que el lector deseoso de curarse con los pseudoterapias de la homeopatía "cayera en la trampa" y leyera la información, la web se tituló http://queeslahomeopatia.com/y logró colarse en la tercera posición de búsqueda de Google ${ }^{5}$. Fue otro acto de protesta -hacker en este caso- para forzar a Google a introducir la verdad científica sobre la homeopatía entre los primeros datos de búsqueda.

Es decir, encontrar información verdadera en Google se torna complicadísimo para personas con escasa formación. Google tiene otro peligro añadido: puede convertir en héroes virtuales a villanos reales. Otro problema de Google es que no diferencia suficientemente entre las web, entre la webs serias y entre la blogosfera. Y, aunque existe una pestaña para los blogs, la mayoría de las veces aparecen confundidos con las webs $\mathrm{y}$, sobre todo, los usuarios no distinguen entre la web del Ministerio de Sanidad o una universidad y cualquier blog. $\mathrm{O}$ entre un blog de un medio serio y otro de un vidente o un charlatán. La jerarquía en Google depende del posicionamiento, no de la veracidad de fuente o información.

En 1998 doctor Andrew Wakefield publicó en la prestigiosa revista médica The Lancet un estudio que vinculaba la vacuna trivírica -sarampión, paperas y rubéola- con casos de autismo. La noticia fue emitida en el press release de la revista médica y difundida en todo el mundo. The Times la situó en portada y un porcentaje importante de padres, presas del pánico, dejaron de vacunar a sus hijos. El sarampión aumentó en todos los países con acceso a Internet y a los medios de comunicación.

Seis años después, en 2004, se descubrió que el autor de ese estudio, el mencionado doctor Andrew Wakefield, había cobrado unos 82.000 euros de una institución -Legal Aid Board- que quería querellarse contra los laboratorios que fabrican esas vacunas. La noticia la desveló un periódico tradicional -The Sunday Times- tras un proceso de investigación periodística interesantísimo. Resalto que no se desveló por un control de la revista; sino que, en este caso, el periodismo fue más riguroso que la ciencia. Ha habido una convergencia en la que el control científico ha sido elaborado por un periódico, no por científicos. The Lancet, tras el reportaje de The Sunday Times, calificó el estudio como "fatalmente equivocado". En enero de 2010 la justicia británica dio la razón a los periodistas y el fallo judicial reconoce que el doctor Wakefield actuó "de forma deshonesta". Por tanto, lo que deben hacer los padres es vacunar a los niños.

Sin embargo, la opinión pública dominante en Internet es que sigue siendo perjudicial y vuelve a observarse un diferencial entre la web y la blogosfera. Si buscamos en Google-web el nombre de "Andrew Wakefield" encontramos 440.000 entradas $^{6}$. En las cinco primeras páginas la casi totalidad de las web hablan del escándalo médico. El perfil de Wakefield que puede obtenerse es el de un impostor científico y se concluye que los niños deben ser vacunados, porque no existe relación entre la vacuna triple vírica y el autismo y, sobre todo, porque el sarampión es una enfermedad vírica que puede tener complicaciones graves. No obstante, cuanto más nos alejamos de la fecha

${ }_{5}^{5}$ Consultado por última vez el 09/05/ 2012.

${ }^{6}$ Consultado el 20 de marzo de 2010 (cinco primeras páginas) 
de la publicación de la sentencia contra Wakefield, van escalando posiciones blogs o sitios webs claramente anticientíficos que lo defienden.

Si buscamos en la blogosfera; es decir, en Google-blog, observamos un gran diferencial con la web. El doctor aparece en 44.200 blogs y en el $42 \%$ de los blogs de las cinco primeras páginas lo defienden. Lo consideran un héroe que lucha contra los laboratorios farmacéuticos que quieren volver a vender su vacuna. ¿Por qué sucede eso? Porque las páginas que aparecen en Google-web están relacionadas con medios de comunicación "tradicionales" e instituciones oficiales. Los motores de búsqueda potencian aquellas webs con más visitas que coinciden, de momento -y mientras los medios de prestigio sigan publicando gratis y en abierto-, con los medios de comunicación consolidados en papel y las instituciones que sirven de fuentes.

Sin embargo, eso no ocurre en la blogosfera: el motor de búsqueda prima los blogs más "vinculados" a otros y, con esa política, los autores de blogs que son muy activos en la red tienen más posibilidades de posicionar mejor sus blogs. Como existe una cantidad importante de blogs que defienden a Wakefield demostraría que los científicos y académicos serios están menos interconectados. Tienen menos presencia en la blogosfera que las personas que creen en las pseudociencias (como la homeopatía) o los antisistemas contrarios a los laboratorios farmacéuticos. Los anticientíficos propician una guerra viral, son mucho más activos en la red y, por tanto, sus blogs están mejor posicionados. Habría que valorar si en el nuevo entorno cibernético los científicos, además, deben tener la obligación de editar su propio blog y participar activamente en las redes sociales.

\subsection{Diferencias entre Google-web y Google-blog}

Esta divergencia entre esfera pública en la blogosfera y la web de Google ocurre con la mayoría de los términos científicos controvertidos. Si analizamos "teléfonos móviles" y "radiación", observamos que en la web aparecen los sitios de las marcas. En ellos siempre se explica que no son perjudiciales para la salud, según todos los informes científicos. También aparece Wikipedia o informes de compañías que sostienen que no son peligrosos. En las cinco primeras páginas de Google-web, el $72 \%$ de las web señalaban que los móviles no emiten radiación perjudicial para la salud humana ${ }^{7}$. Sin embargo, en la blogosfera el panorama cambia radicalmente: el 64\% de los blogs aborda la conexión entre telefonía móvil y cáncer y muchos sostienen que los "científicos están comprados" para no decir la verdad. De esta forma se moldea el "ciberrumor". El ciber-rumor de que no hay que vacunar a los niños porque pueden sufrir autismo o que el teléfono móvil produce cáncer cerebral.

Otros términos científicos de los denominados "controvertidos" como "transgénicos" o "química" también sufren esta distorsión y un tratamiento diferencial entre web y blogosfera. En el caso del término "transgénicos", aparecen en la web 1.150.000 entradas $^{8} \mathrm{y}$ en la blogosfera 224.000 . Un $52 \%$ de las páginas (cinco primeras) de Google-web son informativas con el término (desde Wikipedia hasta el CSIC). Sin em-

7 Consultado el 23 de abril de 2010 (cinco primeras páginas)

8 Consultado el 23 de abril de 2010 (cinco primeras páginas) 
bargo, el $97 \%$ de la blogosfera es negativa. El blog mejor posicionado es el de Greenpeace y su "red de jóvenes contra los transgénicos". El consenso científico respecto a los transgénicos afirma claramente que los transgénicos no tienen por qué ser perjudiciales. De hecho, cualquier producto de la agricultura tradicional es un transgénico, aunque la selección de genes se haya producido por los agricultores eligiendo las mejores variedades de vegetales o - en el caso de granjeros- de animales. Sin embargo, ésa no es la percepción en la red. No existen blogs de profesores universitarios que hablen bien de los transgénicos tan bien posicionados como los de los ecologistas o los amantes de las teorías conspiratorias.

Este fenómeno puede comprobarse en cualquier momento y la condición es que sea un término controvertido. $\mathrm{Si}$, de repente, el término es noticia, puede que cambie su tratamiento en la web en función de cómo lo aborden los medios de calidad. El 20 de abril de 2010 ocurrió una noticia polémica con base científica: unas declaraciones del presidente de Bolivia, Evo Morales, que relacionaba el consumo de transgénicos con la calvicie y la homosexualidad. Aquí detectamos que en la web, dominada por los medios tradicionales en los que el líder boliviano no goza de simpatía, existe un absoluto predominio del enfoque negativo sobre Evo Morales. Sin embargo, en la blogosfera un $41 \%$ de los blog lo defienden ${ }^{10}$.

\section{Discusión. Ciencia para avalar el contraconocimiento}

Resulta curioso cómo las webs que critican a la ciencia usan estudios científicos y enlaces a medios serios para avalar el desprestigio de la ciencia. El objetivo es crear controversia y cuestionar los criterios de autoridad de las fuentes hegemónicas. De esta forma el autor del blog evita que su "rumor" sea refutado por datos científicos. Un estudio usado con frecuencia es uno publicado por El País que señala: "Una gran revista médica pide perdón por evaluar fármacos con expertos pagados por sus fabricantes" (El País, 25-2-2000: 44). En El País la noticia tiene un tratamiento positivo: la honestidad científica que detecta al impostor y lo denuncia. En este caso la revista, The New England Journal of Medicine, una de las revistas especializadas más citadas en suplemento Salud de los Quality papers, se disculpaba porque 19 artículos científicos publicados en los tres últimos años estaban escritos por investigadores que pertenecían a determinados laboratorios farmacéuticos, pero que lo habían ocultado.

Los científicos autores de los artículos elogiaban las propiedades de determinados fármacos respecto de otros, en función de la financiación que percibieran de los laboratorios. Las empresas fueron acusadas de emplear el método de "compra" de un investigador médico para que comentara, con apariencia de objetividad científica, las bondades de un fármaco en esta revista especializada que, a su vez, difundirá sus contenidos en la prensa mundial desde el gabinete de prensa. Entre las multinacionales estaban: Roche, Glaxo Wellcome, Pfizer, Procter and Gamble, Bristol-Myers Squibb, Merk \& Co y Wyeth-Ayerst. Los estudios científicos "comprados" elogiaban los im-

\footnotetext{
9 http://greenpeaceblong.wordpress.com/2010/04/23/la-red-de-jovenes-contra-los-transgenicos/ (consultado por última vez el 23/04/2012)

${ }^{10}$ Consultado el 20/04/2010 (cinco primeras páginas)
} 
portantes resultados de determinados fármacos contra enfermedades como la hepatitis vírica, la meningitis y la osteoporosis.

Esta noticia es citada en los blogs, no como prueba de que las revistas científicas son fiables porque descubren al impostor, sino con un enfoque contrario: no son fiables porque publican estudios comprados por los grandes laboratorios. Es decir, existe una distorsión completa del sentido del contenido del mensaje. Ello favorece que el lector quede totalmente desorientado porque no es capaz de tener un criterio sobre un asunto científico y porque lo que deberían ser fuentes de autoridad quedan difamadas. En periodismo científico se produce el fenómeno de "noticia acatamiento" (Colombo, 1998) en el que, normalmente, la opinión pública no está en concisiones de refutar un resultado científico. Difamando a la fuente se evita el acatamiento a sus resultados y se abona el terreno para cualquier interpretación.

Otro caso similar puede detectarse en un estudio impecable que demuestra la honestidad científica, pues fueron los propios investigadores quienes denuncian a sus compañeros. En 2009 investigadores de la Universidad de Míchigan analizaron 1.534 artículos sobre cáncer publicados en las revistas médicas más importantes del área: New England Journal of Medicine, JAMA, Journal of Clinical Oncology, Journal of the National Cancer Institute, Lancet Oncology, Clinical Cancer Research y Cancer. Publicaron en esta última revista sus resultados y observaron que casi un tercio de los trabajos científicos sobre cáncer tenían algún conflicto de interés con la industria farmacéutica que los patrocinaba (Jagsi et al., 2009). El 62\% de los 261 estudios financiados por la industria se hicieron para ensayar los efectos terapéuticos de un fármaco como posible tratamiento, frente al $36 \%$ de los trabajos no financiados por laboratorios. Y, curiosamente, los estudios con conflicto de interés, tenían más probabilidades de presentar resultados positivos de supervivencia. El estudio publicado, entre otros medios, en El País (22/09/2009), se titulaba "Demasiados conflictos de interés en las investigaciones sobre cáncer", es citado por webs de homeopatía-que es una práctica fraudulenta sin ninguna base científica- para ilustrar sus argumentos contra la medicina tradicional. Estas webs y blogs tienen enlaces tanto a la noticia de El País como al propio estudio, algo que permite el nuevo entorno.

Sin embargo, las universidades no están aprovechando la Red para propiciar una defensa activa del pensamiento científico y desacreditar en el mismo plano todas las informaciones pseudocientíficas.

\section{Conclusión. ¿Quién jerarquiza a Google? Conocimiento vs. contraconoci- miento}

El problema que se plantea es qué pueden hacer las universidades para que ellas lideren la jerarquización en Google de la información sobre términos con una base científica o académica. Hasta ahora, los periodistas tenían esa misión jerarquizadora al seleccionar a las fuentes solventes para cada caso donde no existiera consenso. La gran ventaja que siempre han tenido los periodistas frente al ciudadano común es el acceso directo a las fuentes. Pero ahora ese acceso es compartido con la sociedad. Y nada demuestra que un blog identificado de un profesor universitario o de un científico del CSIC o la NASA no ofrezca una información y análisis más interesante que 
el que procede del periodista. Los weblogs quedan fuera del entramado político-mediático-empresarial de los diarios digitales, muchos internautas se convierten en testigos directos de la realidad informativa.

De hecho, en el periodismo bélico se ha demostrado -por ejemplo, en la invasión de Irak (2003)- que la mejor información procedía de un blog de un joven iraquí llamado "Salam Pax (paz en árabe y en latín)". La filosofía web 2.0 ayudó a que su éxito fuera tan grande que Google, el proveedor del blog, tuvo que replicarlo para que no colapsara. El blog también se convirtió en noticia en los medios tradicionales (no sólo anglosajones, sino que se difundió globalmente). Su información era mucho mejor que la de los periodistas apoltronados -y vigilados- en el Hotel Palestina.

El "profesionalismo" que se ha ido fraguando en todos estos años puede retornar a los orígenes: desaparece el periodista profesional y emerge el experto con habilidades comunicativas. Los últimos acontecimientos mediáticos globales -desde la guerra de Irak hasta la campaña de Obama- nos han hecho comprender que los medios tradicionales se han comportado de una forma esclerótica y han estado marcados por ocultas agendas corporativistas (Kamiya, 2009). Esta puede ser una vía de futuro: desaparece el periodista profesional y emergen los blogs de los expertos. Profesores universitarios que usan todo el potencial de la Red para difundir sus resultados y para intervenir en los murmullos cibernéticos que acontecen en la Red. Pero el problema está en cómo diferenciar los blogs interesantes e informativos de los blogs basura. Cómo se posicionan y cómo se encuentran sin el aval y la ayuda de los medios tradicionales o de alguien muy especializado.

La pauta no puede ser los agregadores o buscadores de noticias. Los agregadores de noticias -el propio Google, por ejemplo- comienzan a verse como medios de comunicación en sí mismos. Youtube es visto como un canal de televisión -y fue usado masivamente en la campaña electoral de Obama en 2008- que compite con $C N N$. La $B B C$ ha anunciado en 2010 un proyecto de las principales cadenas británicas $(B B C$, $I T V, B T$ y Channel 4) para lanzar una plataforma común por Internet, IPTV (Internet Protocol Televisión) que será el futuro de la televisión. Asimismo las portadas de muchos medios se elaboran en función de la selección de los lectores.

Pero la jerarquización ciudadana puede conducir al error, no sólo en ciencia, sino en todos los campos. Si buscamos información en Youtube sobre, por ejemplo, un político, los más vistos y que se mantienen durante más tiempo en las primeras posiciones son los de parodias e insultos. No los de discursos serios que desgranan un programa político. Si introdujéramos, por ejemplo, "Mariano Rajoy" en Youtube, el video más reproducido y comentado en la blogosfera es uno insultante sobre "Rajoy y los pitufos 7 . Esta es la situación más habitual en política -y sucede con políticos de todas las ideologías-, pero los votantes saben aún algo del perfil de los políticos.

Lo grave, desde mi punto de vista, es que esta situación se da también en el conocimiento académico/científico con términos controvertidos como transgénicos, cambio climático o vacunas. La diferencia con otros campos radica en que en ciencia no tenemos referencias para saber a qué atenernos. El rumor -con envíos ciber-virales de videos incluidos- creado en la blogosfera que sostenía que las vacunas contra la gripe A eran peligrosas, provocó que sobraran millones de dosis de esas vacunas. El resul- 
tado no es simplemente un despilfarro económico, sino sanitario: en el futuro podría extenderse con mucha facilidad una grave pandemia entre una población que no se vacunó adecuadamente.

En cualquier caso, este campo de investigación resulta fascinante tanto desde el punto de vista de la comunicación, como del periodismo o de la propia ciencia. El trabajo aquí expuesto sólo representa el comienzo de una línea en la que deberá profundizarse, no sólo para conocer mejor cómo funcionan los mecanismos de comunicación en la era de la sociedad red -que es nuestra razón de ser como investigadores-; sino, sobre todo, para enseñar a los futuros periodistas cómo informar correctamente.

\section{Referencias}

AGULERA, Miguel y PINDADO, Julián. (2006): "Nuevos enfoques en comunicación y salud: perspectivas de investigación". Comunicar, Revista Científica de Comunicación y Educación. 26 (pp. 13-20).

CASTELLS, Manuel (1996): The Information Age: Economy, Society and Culture. Volume I: The Rise of the Network Society. Cambridge. Massachusetts, Blackwell Publishers.

COLOMBO, Furio. (1998): Últimas noticias sobre periodismo. Barcelona, Bosch.

DIMITROPOULOU, Polyxeni et al. (2009): "Sexual activity and préstate cancer risk in men diagnosed at a younger age". BJU International. 103(2): 178-185.

ELIAS, Carlos (2009): "La "cultura convergente" y la filosofía Web 2.0 en la reformulación de la comunicación científica en la era del ciberperiodismo". Arbor, ciencia, pensamiento y cultura. 737: 623-634.

FLORES VIVAR, Jesús Miguel (2009): "Nuevos modelos de comunicación, perfiles y tendencias en las redes sociales". Comunicar, Revista Científica de Comunicación y Educación. 33 (pp. 73-81).

JAGSI, Reshma et al. (2009):"Frecuency, nature, effects and correlates of conflicts of interest in published clinical cancer research". Cancer, vol 115, 12, (pp. 27832791)

JENKINS, Henry (2006): Convergence culture. Nueva York, New York Univerity Press (Versión en español en Paidóss, 2008)

KAMIYA, Gary (2009): "The death of the news". Salon.com (17-02-2009)

LÉVI, Pierre (1997): Collective Intelligence: Mankind's Emerging world in Cyberspace. Cambridge, Perseus Book.

PORTER, Roy (2000): Quaks: Fakers and Charlatans in English Medicine. London,Tempus.

RHEINGOLD, Howard (2003): Smart Mobs: The next social revolution. New York, Basic Book.

THOMPSON, Damian (2009): Los nuevos charlatanes. Barcelona, Ares y Mares (Crítica). 